\title{
Review
}

\section{NONLINEAR LOCALIZATION OF LIGHT*}

\author{
A. Dubietis, G. Valiulis, and A. Varanavičius \\ Department of Quantum Electronics, Vilnius University, Sauletekio 9, LT-10222 Vilnius, Lithuania \\ E-mail: audrius.dubietis@ff.vu.lt
}

Received 1 September 2005

\begin{abstract}
We briefly overview historical, fundamental, and practical aspects of light wave propagation, where strong multidimensional localization and precise control of ultrashort signals is demanded. The main topic is focused on the state of art of recently discovered nonlinear conical waves, or so-called X-shaped light bullets, which have been demonstrated to appear spontaneously in many different, frequently encountered operating regimes in transparent gaseous, liquid, and solid media. Owing to unique features of white-light frequency spectrum, strong localization, deep-field stationarity, and hot-spot regeneration property, nonlinear conical waves have great potential in all applications requiring energy transfer to matter over very limited transverse areas in thick media, which thus suffer the short focal depth of conventional laser beams. Practical applications that cover many different areas ranging from nano-science to high-field physics are discussed.
\end{abstract}

Keywords: light bullets, $\mathrm{X}$ waves and X pulses, Bessel beams, light filaments, conical waves, solitons, self-focusing

PACS: $41.20 . \mathrm{Jb}, 42.25 . \mathrm{Bs}, 42.65 . \mathrm{Re}$, 42.65.Jx

\section{Introduction}

Laser is one of the most important optical devices invented during past 50 years. Because of unique properties of laser light, laser applications nowadays cover almost entire scope of modern science - physics, chemistry, biology, medicine, technology, etc. One of the challenging tasks in modern optics is to overcome the natural spreading of ultrashort wave packets caused by diffraction and dispersion [1]. Since ultrashort wave packet is composed by a number of electromagnetic waves of different spatial and temporal frequencies being phase-locked in time and in space, in the medium these waves propagate with slightly different group velocity because of chromatic dispersion and with some angular divergence because of diffraction, see Fig. 1. Propagation of ultrashort wave packet in transparent dispersive media is described by the standard paraxial propagation equation

$$
\mathrm{i} \frac{\partial A}{\partial z}-\frac{k^{\prime \prime}}{2} \frac{\partial^{2} A}{\partial t^{2}}+\frac{1}{2 k_{0}} \nabla_{\perp}^{2} A=0
$$

where $A$ is the complex field amplitude, $\nabla_{\perp}^{2}=$ $\partial^{2} / \partial x^{2}+\partial^{2} / \partial y^{2}$ is the Laplace operator perpendicular to the propagation direction $z, k^{\prime \prime}=d^{2} k / d \omega^{2}$ is the material group velocity dispersion, $k_{0}=2 \pi / \lambda$

\footnotetext{
* The report presented at the 36th Lithuanian National Physics Conference, 16-18 June 2005, Vilnius, Lithuania.
}

is the propagation constant, with $\lambda$ being the wavelength. Left-hand terms 2 and 3 stand for dispersion and diffraction, respectively. Dispersion is normal if $k^{\prime \prime}>0$ and anomalous if $k^{\prime \prime}<0$. For conventional, bell-shaped Gaussian wave packet with temporal duration $t_{p}$ and beam width $w_{0}$

$$
A(r, t, 0)=A_{0} \exp \left(-\frac{r^{2}}{w_{0}^{2}}-\frac{t^{2}}{t_{p}^{2}}\right)
$$

characteristic lengths for beam spatial spread (Rayleigh range, $z_{\mathrm{R}}$ ) and pulsewidth broadening (dispersive length, $L_{\mathrm{d}}$ ), representing a change of corresponding values by $\sqrt{2}$ are expressed as

$$
z_{\mathrm{R}}=\frac{\pi n w_{0}^{2}}{\lambda}, \quad L_{\mathrm{d}}=\frac{t_{p}^{2}}{\left|k^{\prime \prime}\right|} .
$$

The smaller the dimension of the beam and the shorter the pulse width, the more pronounced effects of diffractive spread and dispersive broadening do occur. For instance, diffraction and dispersion lengths for $10 \mathrm{fs}, 10 \mu \mathrm{m}$ Gaussian wave packet with wavelength centred at $527 \mathrm{~nm}$ propagating in a bulk glass sample are $z_{\mathrm{R}} \simeq 1 \mathrm{~mm}$ and $L_{\mathrm{d}} \simeq 3 \mathrm{~mm}$, respectively. Therefore the quest for wave packets that are localized in all dimensions and are propagation invariants (defeating the natural spread) is of primary importance in the context involving wave propagation and 


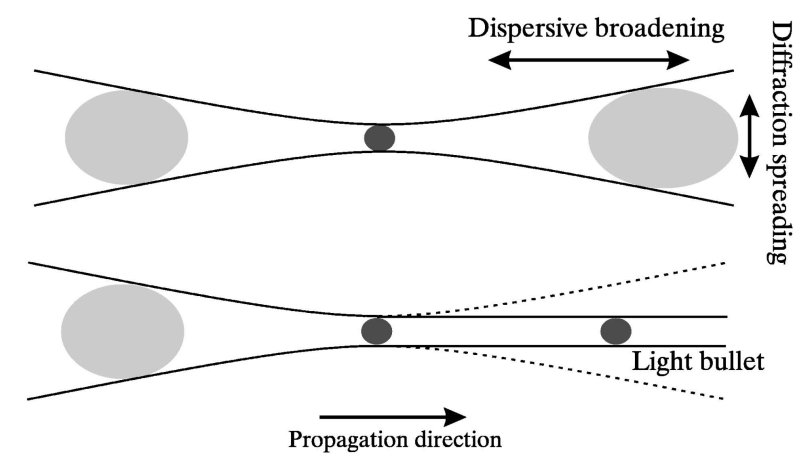

Fig. 1. Simplified representation of the localized wave packet. Top: effect of diffraction and dispersion on spatiotemporal dimensions of the wave packet in dispersive medium. Bottom: non-diffracting and non-dispersing wave packet - light bullet.

light-matter interactions. Two standard approaches have been previously considered for obtaining wave packet stationarity and multidimensional (spatiotemporal) localization: the linear approach, based on conical waves, and the nonlinear approach, based on solitons. Unfortunately, both have serious drawbacks from the viewpoint of practical applications; the linear scheme owing to weak localization and poor contrast, and the nonlinear scheme owing to dominant energy dissipation (nonlinear losses). Combining of the two paradigms of linear conical and nonlinear solitary waves has led to discovery of nonlinear conical waves, with exceptional feature of coexistence of a localized high-intensity core and extended, high energy, but low intensity beam periphery, which travel locked in a single (quasi)stationary profile.

In this paper we provide a brief review of localized wave packets accessible by means of linear and nonlinear optics: optical solitons, nondiffracting (Bessel or Durnin) beams, light filaments, and $\mathrm{X}$ waves, their fundamental background, practical realizations, and potential impact to ongoing fundamental research and applied science.

\section{Historical overview}

Localized waves in physics are known for more than one and a half century. In 1834 Scottish engineer Scott Russell in narrow barge channel near Edinburgh discovered water surface waves that propagate for miles without apparent change in amplitude and speed [2]. Originally called "translation waves", later these waves were named solitons. In modern understanding, solitons are strongly localized waves preserving or periodically rebuilding their shape during propagation. Solitons in the realm of optics were made possible with the advent of ultrashort pulse lasers and optical fibres, seeking to use them as an information bits for modern optical communication and information processing [3]. Solitary waves are entirely nonlinear entities; their stationarity derives from self-interaction of the wave, which requires specific nonlinearities, intensity levels, beam sizes, or pulse widths. In 1990 Silberberg has foreseen that nonlinear effects in bulk media combined with anomalous dispersion might readily compensate for dispersive and diffractive spread, resulting in full dimensional localization of the wave packet, and introduced the term of "optical bullets" - spatiotemporal solitons [4]. To date, spatial and temporal solitons were experimentally demonstrated under variety of operating conditions, see review article [5]. However, solitons carry a limited, well-defined energy content, what makes them not robust against nonlinear losses (energy dissipation) that inevitably occur from extremely high intensities and destroy the precise nonlinear balance of the self-acting wave. Therefore no stable multidimensional soliton in any real physical system has been experimentally demonstrated up to now [6].

An alternative approach in attempting the generation of localized and stationary wave packets is based on conical waves. Original ideas of propagationinvariant electromagnetic fields in linear systems date back to the beginning of the 20th century, when Bateman [7] and later Stratton [8] have foreseen the existence of a propagation-invariant solutions to Maxwell equations. Unfortunately, their ideas were forgotten for a long time, and only in 1987 Durnin and coworkers rediscovered [9] and for the first time experimentally demonstrated the non-diffracting light beams [10], which had specific radial intensity distribution described by Bessel function:

$$
A(r, z)=A_{0} \exp \left(\mathrm{i} k_{z} z\right) J_{0}\left(k_{r} r\right)
$$

where $J_{0}$ is the lowest order Bessel function, $k_{z}$ and $k_{r}$ are longitudinal and radial wave vectors, with $k=$ $\sqrt{k_{z}^{2}+k_{r}^{2}}=2 \pi / \lambda$, and $r, z$ are radial and longitudinal components, respectively. The intensity profile of a Bessel beam is shown in Fig. 2(b).

Experimental realization of non-diffracting beams relies upon using optical elements, such as annular slits, holographic elements, or most efficiently, conical lenses - axicons. These methods are discussed in great detail in Ref. [11]. Peculiar feature of non-diffracting, so-called Bessel or Durnin beams is that the energy flow is not directed along the propagation axis, as in conventional Gaussian-like beams, see Fig. 2(a). Here energy arrives laterally, from the cone-shaped surface, 


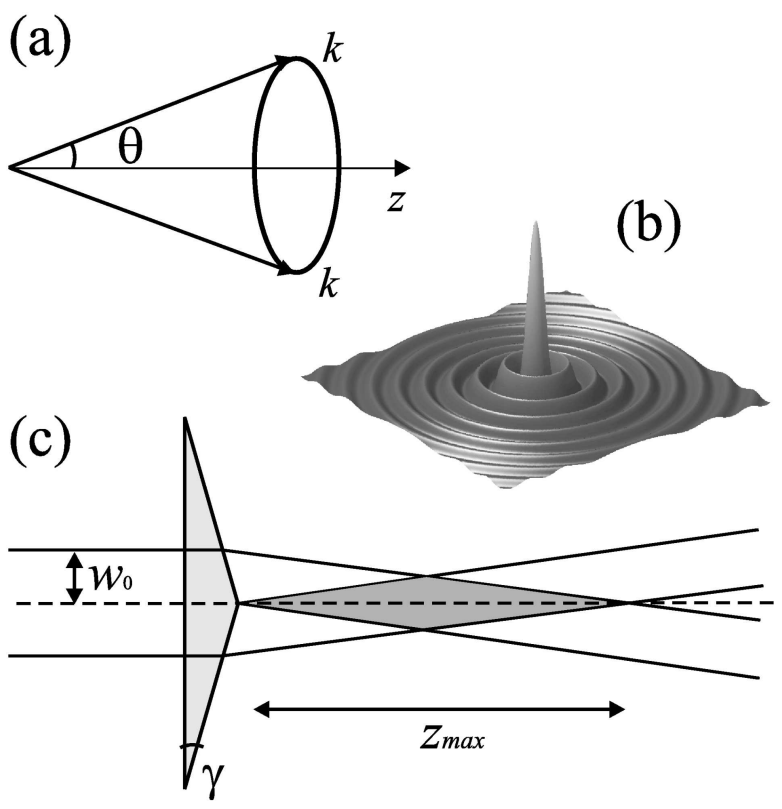

Fig. 2. (a) Wave vectors of the Bessel beam lie along cone-shaped surface, (b) intensity profile of the Bessel beam, (c) production of a Bessel beam by an axicon. Shaded area highlights the Bessel zone of length $z_{\max }$, see text for details.

leading to appearance of a very intense and localized interference peak down to few wavelengths in dimension as shown in Fig. 2(b), which propagates free of diffraction spreading. Such a peak is supported by the presence of slowly decaying tails in the form of concentric rings that contain a major part of energy (each ring carries an equal amount of energy). Due to finite energy extent and particular geometry of practical realization, the non-diffracting propagation is limited to finite distances, though orders of magnitude larger than those achievable by conventional beams. For instance, axicon-generated Bessel beam has the depth of a Bessel zone $z_{\max } \approx w_{0} / \theta$, which far exceeds the Rayleigh range of a Gaussian beam of the same width, see Fig. 2(c). Here $w_{0}$ denotes input beam diameter and $\theta$ is the cone angle related to an opening angle $\gamma$ of the axicon by $\theta=(n-1) \gamma$.

Ten years later, Saari and Reivelt generalized the idea of monochromatic non-diffracting beams for polychromatic beams that carry ultrashort light pulses [12]. They have demonstrated that colored cones, corresponding to each frequency, if properly composed, produce so-called linear $\mathrm{X}$ wave, which shares both nondiffracting and non-dispersing properties as it propagates in dispersive medium. More detailed analysis revealed that diffraction of pulsed beams can be formulated as an anomalously dispersive phenomenon, which causes the diffraction effects and dispersion spreading to cancel each other to a great extent, if transverse beam profile is suitably chosen [13]. To this regard, realization of localized broadband optical fields carrying even subcycle optical pulses was shown to be possible [14], and recently non-diffracting and non-dispersing sub-10 fs X-pulses with dimensions down to few wavelengths were experimentally demonstrated [15]. However, because of poor intensity contrast the discovery of linear X waves until now has not made a real breakthrough in practical applications.

\section{Self-focusing of optical wave packets}

In nonlinear optics, physical mechanisms leading to localization of light are much more complex and possess rich phenomenology. Discovery of self-focusing and collapse of high-power laser pulses in transparent media marks the birth of nonlinear optics shortly after the invention of the laser [16]. Since the dawn of laser era the phenomenon of wave collapse because of its universality continuously attracts significant attention from the scientific community [17]. Self-focusing of the light wave is governed by the optical Kerr effect, which temporarily modifies refractive index of the material:

$$
\Delta n(r, t)=n_{2} I(r, t),
$$

here $n_{2}$ is the nonlinear refractive index linked to thirdorder susceptibility and $I(r, t)$ is the intensity. The effect of self-focusing becomes detrimental upon reaching so-called critical power of the beam

$$
P_{\mathrm{cr}}=\frac{3.77 \lambda^{2}}{8 \pi n n_{2}}
$$

which is governed by the compensation of natural beam divergence by self-focusing effect.

In the pioneering experiments, self-focusing of high power optical beams, operated in long-pulse or continuous wave mode, has been tightly linked to uncontrolled optical breakdown phenomena. Only with the advent of ultrashort lasers, self-focusing of femtosecond light pulses in transparent media has been shown to give rise to a variety of physical effects: beam filamentation, conical emission, white-light continuum generation, nonlinear absorption, ionization, space-time transformations, without apparent onset of material breakdown, and still remains a hot topic of theoretical and experimental research [18]. With femtosecond pulses, collapse arresting mechanisms such as pulse lengthening due to normal group velocity dispersion or plasma defocusing come into play, thus preventing catastrophic 
contraction of the beam. In the last decade, considerable knowledge on self-focusing phenomena has been accumulated, thanks to a revived interest on the topic inspired by the observation of long-range propagation of femtosecond light filaments in air [19].
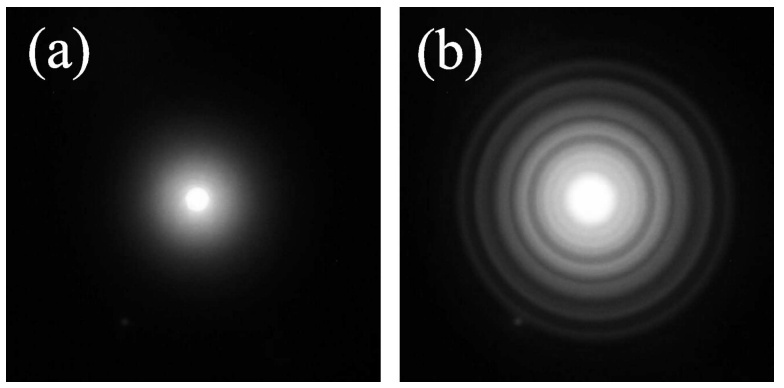

Fig. 3. Two screen shots illustrating the far field of light filament in water - white-light axial radiation surrounded by color rings. Input power: (a) $4 P_{\mathrm{cr}}$, (b) $10 P_{\mathrm{cr}}$. Very similar structure is observed with light filaments in air and fused silica.

To this regard, many interesting and even unexpected findings were disclosed, which have a potential impact on complete understanding of the underlying physics and promote a series of potential applications as well. Observations of light filaments in air [20-22], solids [23, 24], and liquids [25-27] had been reported to date, all revealing the universality of the physical processes involved despite very distinct operating conditions. In Fig. 3 typical far-field images of the beam, which has undergone self-focusing are shown. The widely accepted filamentation scenario is based upon self-channelled propagation governing from the dynamic balance between self-focusing, diffraction, and defocusing effect of free electron plasma, created via multiphoton ionization.

Propagation of an ultrashort wave packet in nonlinear media is governed by the nonlinear Schrödinger equation

$$
\begin{gathered}
\mathrm{i} \frac{\partial A}{\partial z}-\frac{k^{\prime \prime}}{2} \frac{\partial^{2} A}{\partial t^{2}}+\frac{1}{2 k_{0}} \nabla_{\perp}^{2} A+\frac{\omega_{0} n_{2}}{c}|A|^{2} A \\
+\mathrm{i} \frac{\beta^{(K)}}{2}|A|^{2 K-2} A=0,
\end{gathered}
$$

where $\omega_{0}$ is the carrier frequency, $\beta^{(K)}$ is the multiphoton absorption coefficient, with $K$ being the order of the process. Terms 2 and 3 represent diffraction and dispersion as in Eq. (1), while nonlinear terms 4 and 5 stand for self-focusing and multiphoton absorption, respectively. With account for plasma defocusing, equation takes more complex form, including evolution equation for the free electron density, which accounts also for multiphoton and avalanche ionization, plasma absorption, optical shock terms, etc., see the full model described in [28]. However, some basic properties can be evaluated with the help of the propagation equation in the simplified form as given by Eq. (7). A numerical simulation in the frame of a continuous wave model that accounted only for diffraction, Kerr focusing, and nonlinear losses (Eq. (7) without temporal terms) suggested a possible scenario where all temporal effects as well as those related to plasma induced defocusing or saturation of the nonlinearity could be not essential to the occurrence of the apparent guiding effect. Indeed, the spontaneous transformation of a Gaussian beam into a conical wave is driven by the interplay of self-focusing, nonlinear losses (multiphoton absorption), and diffraction [29]. The self-built conical wave consists of localized intense hot part (central spike, usually called filament) and extended low intensity periphery (which, however, carries a major part of the energy) that travels continuously refilling the hot portion of the wave.

In support of the conical wave model, an experiment by clipping or stopping a light filament while it propagates in water (Fig. 4) has proven that it does not behave as a self-channelled wave packet, being structurally sustained by a strong energy flux from the surrounding beam. In the case of clipped beam periphery (just the central spike transmitted through the pinhole), the filament rapidly diffracts and does not survive anymore. By contrast, blocked central spike (with beam stopper inside water cell) is quickly rebuilt by the energy flux from the beam periphery. Reconstruction effect was also observed in the linear propagation regime, i. e. outside the water cell, justifying the conical nature of spontaneously built wave [30]. Recent research in connection with air filaments has arrived to similar results, demonstrating self-reconstruction property of air filaments when colliding with water droplets [31], and immediate termination of filamentation process if the beam periphery is removed [32].

In presence of nonlinear losses, the time-integrated spatial profile evolves towards unbalanced Bessel beam, being composed of inward and outward Hankel beams with unequal weights [33]:

$A \simeq \frac{A_{0}}{2}\left[\alpha_{\text {out }} H_{0}^{(1)}(\sqrt{2 k \delta r})+\alpha_{\text {in }} H_{0}^{(2)}(\sqrt{2 k \delta r})\right] \mathrm{e}^{-\mathrm{i} k \delta}$,

where $H_{0}^{(1,2)}$ are Hankel functions of the first and second kind, $\delta$ is the wave vector shift related to cone 

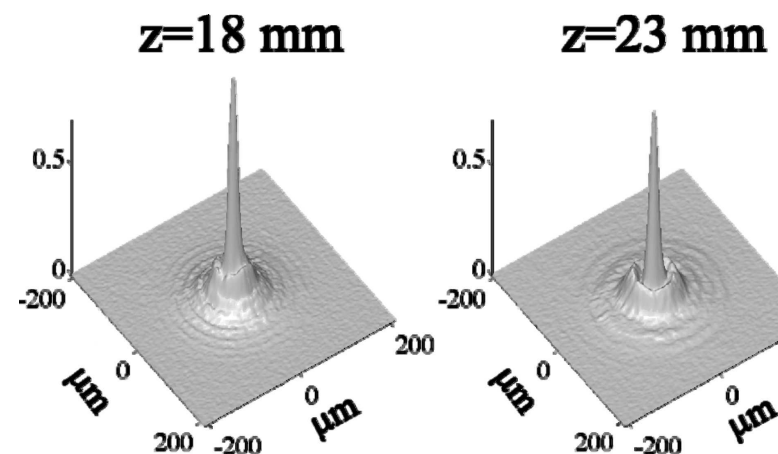

$\mathrm{z}=30 \mathrm{~mm}$

$\mathrm{z}=40 \mathrm{~mm}$
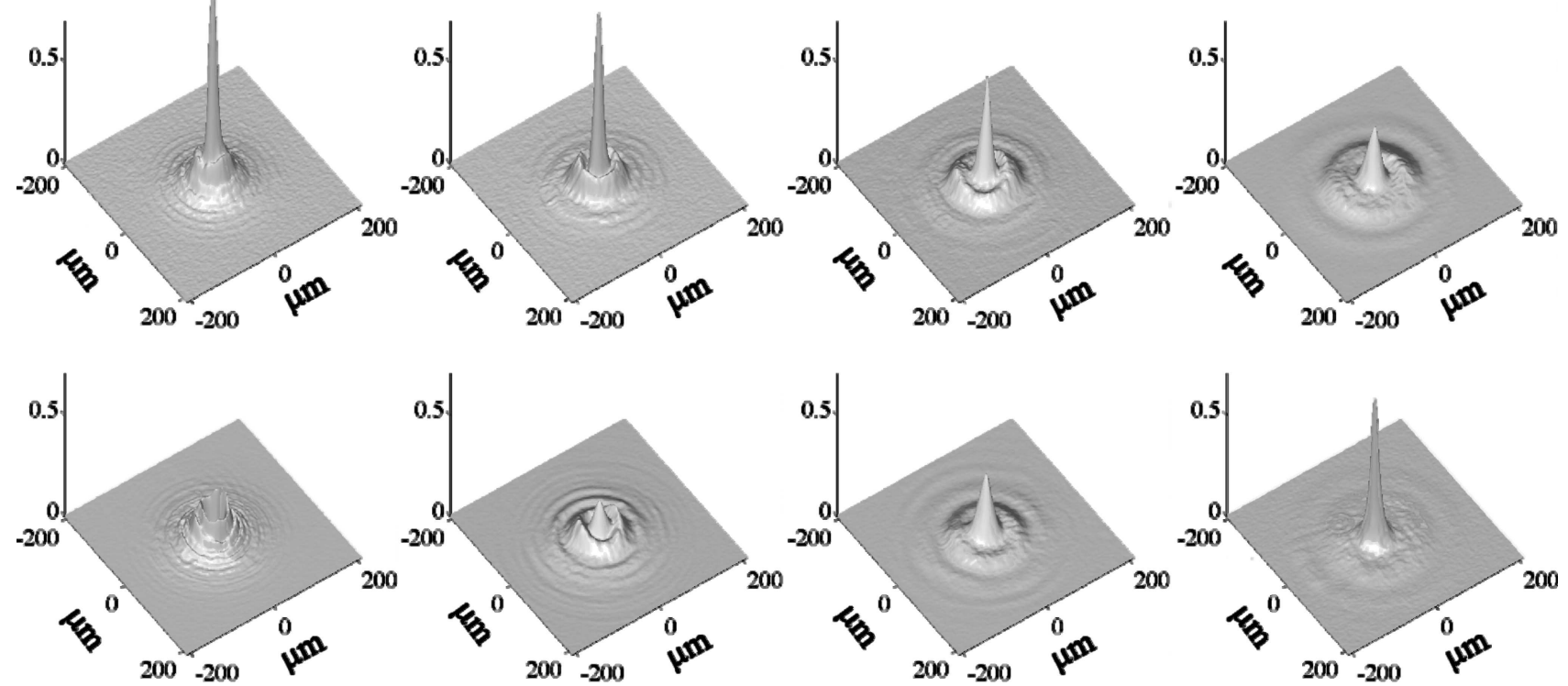

$\mathrm{z}=18 \mathrm{~mm}$

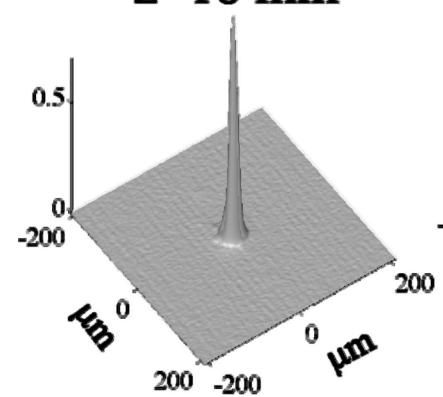

$\mathrm{z}=20 \mathrm{~mm}$

$\mathrm{z}=25 \mathrm{~mm}$
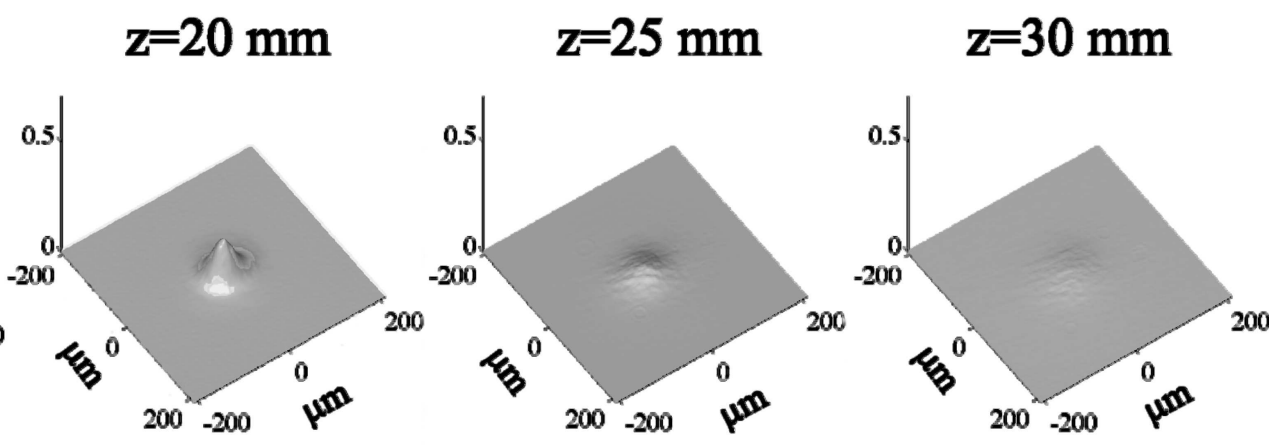

Fig. 4. Basic features of femtosecond light filaments in water: free propagation (top), self-reconstruction of the central spike (centre), and decay of the central spike with blocked periphery (bottom). Note also different scales for propagation length $z$. See Ref. [30] for details.

angle $\theta=\sqrt{2 \delta / k}$, and $\alpha_{\text {out }}$ and $\alpha_{\text {in }}$ represent different weights related by

$$
A_{0}\left(\left|\alpha_{\text {in }}\right|^{2}-\left|\alpha_{\text {out }}\right|^{2}\right) / k=N_{\infty}
$$

where $N_{\infty}$ denotes the total nonlinear losses. Note that the balanced superposition of Hankel beams $\left(\alpha_{\text {out }}=\right.$ $\alpha_{\text {in }}=1$ ) yields just original Bessel beam as described by Eq. (4). The striking feature of the unbalanced Bessel beam is that unbalancing creates a net inward radial energy flux that compensates for nonlinear losses. Therefore, the latter finding points out that conical waves in continuous wave limit are stationary and localized solutions of Eq. (7) being robust in presence of nonlinear losses. As will be shown in the following section, spatiotemporal structure of light filaments in media with cubic nonlinearity closely resembles that of the nonlinear $\mathrm{X}$ waves.

\section{Nonlinear X-waves - conical light bullets}

As outlined in previous section, spatiotemporal solitons (or bell-shaped light bullets) require strictly anomalous group velocity dispersion, which if combined with self-action, suitably balances diffraction and dispersion effects. Normal group velocity dispersion, featured to be characteristic for most transparent media in the ultraviolet, visible, and near infrared spectral range, rules out the possibility of achieving solitontype localized wave packets. Nevertheless, recently it has been predicted and demonstrated that space-time localization becomes accessible in the normal group velocity dispersion in the nonlinear regime considering a novel, non-standard approach of conical wave packets $-X$ waves [34]. As follows from the linear $X$ wave analysis, propagation-invariant wave packet can be achieved whenever its spatiotemporal spectrum in 
$\left(k_{\perp}, \Omega\right)$ domain asymptotically fits the dispersion relationship

$$
\beta=k^{\prime \prime} \Omega^{2} / 2-k_{\perp}^{2} /\left(2 k_{0}\right)=\text { const },
$$

which in the case of normal group velocity dispersion represents a family of hyperbolas following from the propagation equation (Eq. (1)). Here $k_{\perp}$ is the transverse wave vector, related to cone angle $\theta \simeq k_{\perp} / k_{0}$, and $\Omega=\omega-\omega_{0}$ is the frequency detuning from the carrier frequency. Angularly resolved spectral shape resembles X profile associated with the lines $\beta=0$,

$$
k_{\perp}= \pm \sqrt{2 k_{0} k^{\prime \prime}} \Omega .
$$

If spectral components are in phase, the spatiotemporal electric field distribution also retains an X-shaped profile (as shown in Fig. 5):

$$
E(r, t)=\operatorname{Re} \frac{1}{\sqrt{(\Delta-\mathrm{i} t)^{2}+k_{0} k^{\prime \prime} r^{2}}},
$$

where $\Delta$ represents time duration of the central peak. The first experimental evidence of the $\mathrm{X}$ wave formation during nonlinear optical process has been reported by Valiulis and co-authors [34]. In contrast to linear $\mathrm{X}$ waves, which require complex beam shaping, nonlinear $\mathrm{X}$ waves spontaneously reshape from the initial Gaussian wave packet. In the second-harmonic generation experiment (in birefringent crystals possessing quadratic nonlinearity), the spontaneous reshaping was shown to be driven by mutual balance between selffocusing nonlinearity arising from phase-mismatched interaction and dispersive contribution, which resembles an effective anomalous group velocity dispersion through the angular dispersion $[35,36]$.

Although the initial experiment on strong space-time localization has indicated an apparent axial compression of the wave packet in both (spatial and temporal) dimensions [37], intrinsic spatiotemporal structure of the $\mathrm{X}$ wave suggests that considerable amount of energy should be stored out of axis, in slowly decaying tails. Indeed, high resolution, high dynamic range three-dimensional mapping revealed spatiotemporal intensity profile, which resembled closely essential features of an X wave - strongly localized central peak and slowly decaying conical tails, see Fig. 6 [38]. The proposed measurement technique involved temporal slicing of the conical (in general case, arbitrarily shaped) wave packet by an extremely short ( $\sim 10$ fs) Gaussian pulse, having almost constant radial intensity distribution, by means of conventional cross-correlation method based on sum-frequency mixing. However, a major improvement to standard correlation technique

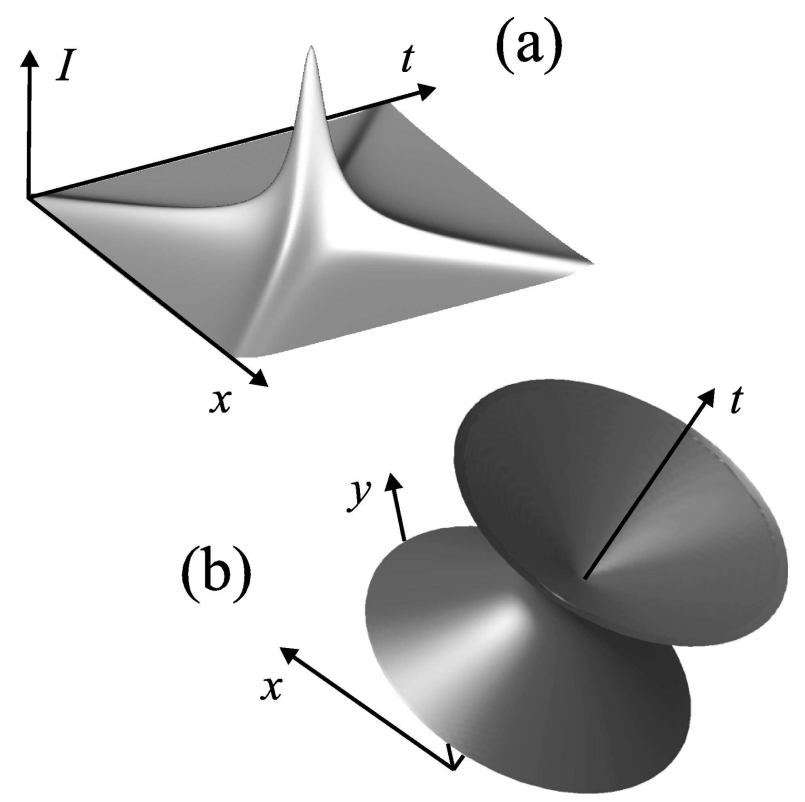

Fig. 5. Three dimensional representation of the $X$ wave: (a) spatiotemporal intensity $(x, t, I)$ profile and (b) iso-intensity surface $\left(x, y, t, I=\right.$ const) at the intensity level $0.1 I_{\text {max }}$.

is that ultimate resolution not only in time, but more importantly, also in space, is achieved [39].

Recently, femtosecond filamentation in media with cubic nonlinearity, namely water has been interpreted in terms of dynamic nonlinear $\mathrm{X}$ waves, whose propagation follows from the interplay of nonlinearity and chromatic dispersion [40,41]. Authors have explicitly demonstrated that spatiotemporal spectra acquire the form of the X, being mediated by wave mixing and dispersion imposed phase matching. Moreover, authors predicted axial pulse splitting and subsequent replenishment of the pulse centre, which was at the same time independently observed experimentally by means of aforementioned three dimensional mapping technique, as shown in Fig. 7 [42].

Spectral-angular measurements by imaging spectrometer have shown that indeed angles of conical emission from light filaments obey the asymptotics of the dispersion relation given by Eq. (10), with increasing cone angles for both negative and positive detunings from the carrier frequency [43]. An example of angularly resolved frequency spectrum is shown in Fig. 8. The full map of spatiotemporal transformations outlines complex dynamics, initially dominated by nonlinear losses, then by self-focusing and pulse splitting, eventually leading to the formation of an $\mathrm{X}$-shaped object surrounded by a complicated background [44]. Numerical simulations using a model developed for femtosecond filamentation in liquids solids and gasses confirms the experimental observations, and 
(a)
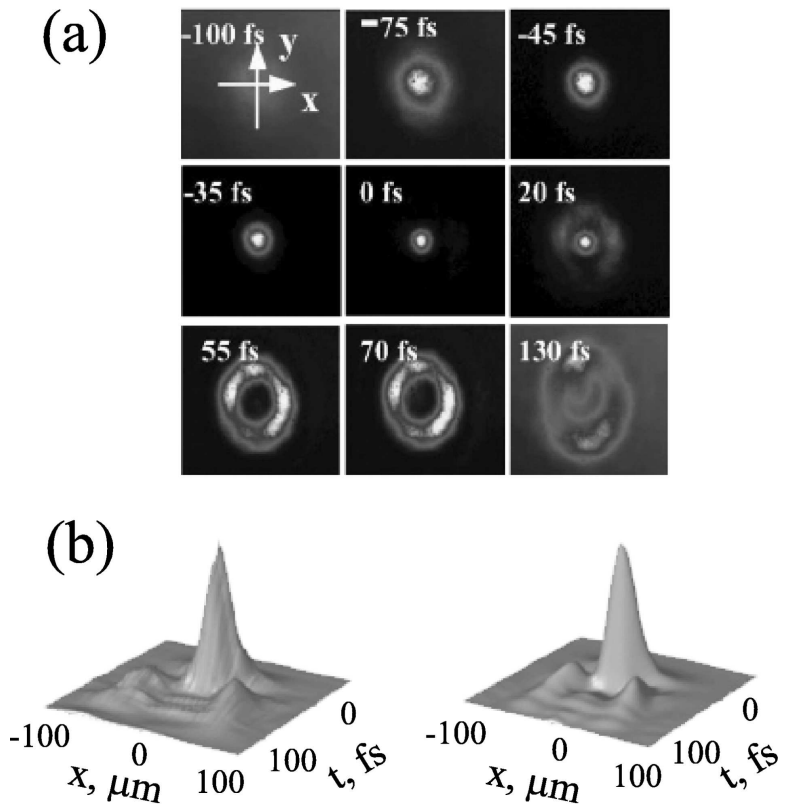

(c)
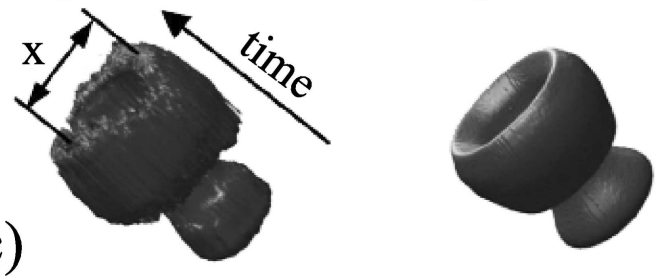

Fig. 6. Spatiotemporal intensity profiles of the nonlinear $\mathrm{X}$ wave excited by phase-mismatched second harmonic generation in lithium triborate (LBO) crystal: the results make evident nonlinear beam compression, accompanied by a non-Gaussian redistribution of the wave packet fluence. (a) Transverse profiles of sum-frequency fluence for different delays, (b) experimental (left) and simulated (right) intensity map of the $\mathrm{X}$ wave as captured after $5 \mathrm{~mm}$ of free-space propagation, and (c) experimental (left) and simulated (right) iso-intensity surface at the intensity level $0.07 I_{\max }$. The details of experiment are described elsewhere [38].
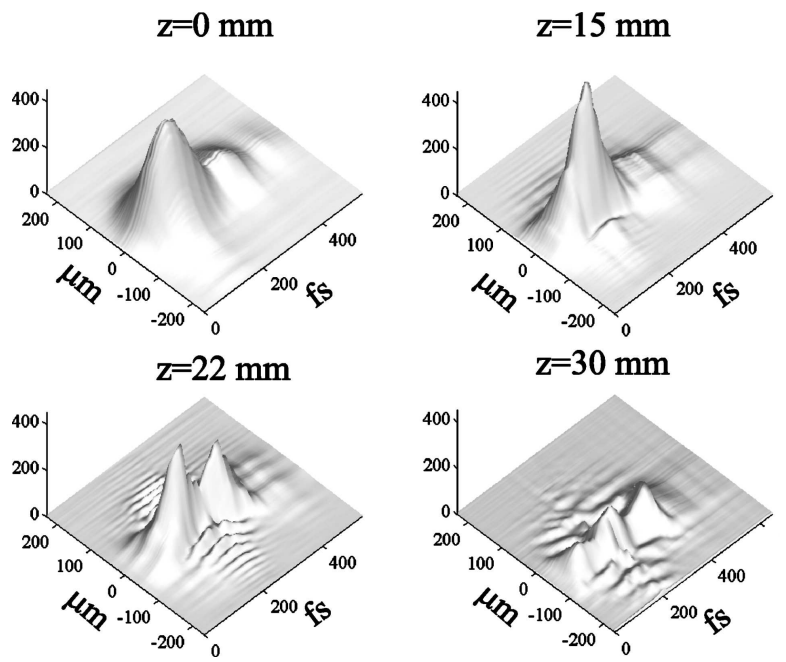

Fig. 7. Spatiotemporal transformation of $150 \mathrm{fs}$ wave packets in water at $5 P_{\mathrm{cr}}$. Here $z$ denotes the propagation length. most importantly, nonlinear $\mathrm{X}$ wave generation is foreseen for a wide parameter range, whatever is the physical mechanism arresting the collapse [28].

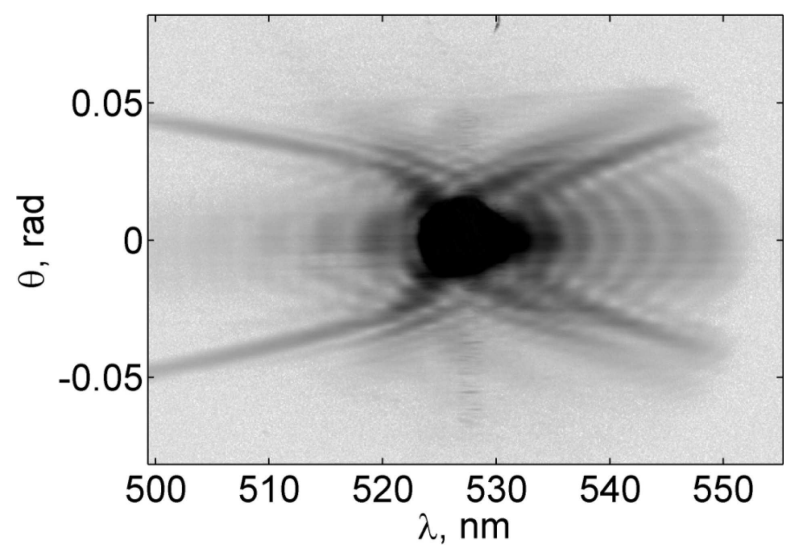

Fig. 8. Spectral-angular distribution of the light filament in water, excited by $1 \mathrm{ps}, 527 \mathrm{~nm}$ pulses and measured by imaging spectrometer.

Another relevant and still poorly investigated case refers to filamentation phenomena in the regime of anomalous group velocity dispersion. Preliminary experiments and numerical simulations suggest extended filamentation lengths in fused silica at telecom (around $1.5 \mu \mathrm{m})$ wavelengths $[45,46]$. Comprehensive numerical analysis shows that in this case the resulting wave packet should be described in terms of nonlinear O-waves [47].

Increasing relevance of the $\mathrm{X}$ waves in optics becomes recognized also in the operating regimes different from Kerr-effect mediated phenomena: it has been predicted and demonstrated experimentally that nonlinear $\mathrm{X}$ waves are intrinsic modes of the parametric fluorescence excited in crystals with second-order nonlinearity [48]. More recently, spontaneous formation of X waves in photonic crystals [49] and waveguide arrays [50] has been foreseen.

\section{Emerging applications}

As described in previous sections, a broad class of conical waves (Bessel beams, light filaments, linear and nonlinear $\mathrm{X}$ waves) share properties of nondiffractive and nondispersive (for pulses) propagation of highly localized central peak being surrounded by low intensity energy reservoir. Due to conical nature, self-reconstruction appears to be an intrinsic property of conical waves, guaranteeing stationarity by the refilling effect. Owing to unique properties not present in conventional bell-shaped (Gaussian) wave packets, 
conical waves in the nonlinear regime, where matter only responds to the localized high intensity peak, being totally transparent to the weak tails, open a wide range of applications, which are inefficient or even not accessible by means of conventional laser beams.

Existing methods for light detection and ranging (LIDAR) based on backscatter signal are shown to be substantially improved by application of long-range propagating white-light filaments in air [51]. The potential applications include determining both the chemical and dynamic processes that affect problems such as global warming, ozone loss, tropospheric pollution, and weather prediction. The use of white-light LIDAR promises several advantages over conventional detection methods: light filaments transmit the energy onto the target area without apparent diffraction losses, with substantially improved signal-to-noise ratio. Most importantly, broadband detection in a single shot becomes available, and no tunable laser therefore is required. Great penetration depth allows precise tracing of atmospheric gases, as well as aerosol abundance, particle size, etc. Using of pre-chirped light pulses allows control over filament formation dynamics and filamentation length; to the best of knowledge, kilometre-long white-light filaments reaching $10 \mathrm{~km}$ height have been demonstrated [52].

Long-range propagation is particularly useful for efficient generation of the third harmonic in air and for high-order harmonics generation in noble gasses [53]. Besides frequency conversion, amplification of backscattered fluorescence of nitrogen molecules by the ultrashort light filament, i.e. laser action in air has been observed [54]. The ionized trail induced by femtosecond light filaments in air has been considered to be useful for triggering and guiding the electrical discharges for lightning protection [55]. Indeed, light filament by means of multiphoton ionization produces short-lived conducting narrow plasma channel that might readily serve as a precursor for a discharge. A number of laboratory experiments has proven the validity of proposed approach, and laser guided megavolt discharges with spark lengths up to $3.8 \mathrm{~m}$ have been reported to date [56]. More recently, artificial laboratory lightning has been demonstrated by simulating real atmospheric conditions - fog and rain, thus bringing the research close to real-scale lightning control applications [57].

In the condensed media, owing to their non-diffracting properties Bessel beams are put to use in a number of specific applications. These cover atom optics, particle physics, optical microprocessing, to mention a few. The most exiting achievement is the demonstration of micromanipulation of small objects in multiple planes - three dimensional optical tweezer [58] and realization of optical levitation of particles [59]. Trapping of cavitation bubbles in water with femtosecond light filaments has been demonstrated as well [60]. In material processing, Bessel beams were found to be useful for microlitography [61] and optical microstructuring of the materials [62] with ultimate precision. Because of very local ionization within transparent materials, light filaments readily produce single shot longitudinal illumination and introduce permanent volumetric refractive index change in transparent bulk media for designing optical waveguides and photonic structures [63]. More recently, high resolution, high focal depth, and high contrast fluorescence channels excited by means of three-photon absorption of Coumarine 120 dye in methanol with Bessel beams has been demonstrated offering new applications in multiphoton microscopy [64].

In nonlinear optics, Bessel beams promise an interesting physics [65] and practical benefits, in particular for generation of diffraction-limited parametric superfluorescence and for production of coherent radiation from incoherent light sources desirable for device applications [66].

And finally, fundamental knowledge on nonlinear localization of light, accumulated during the last decade greatly benefits the laser physics itself and opens new prospects in advancing new generation, socalled white-light laser [67]. To this regard, table-top, millijoule-level, few optical cycle pulses become feasible through ultrashort pulse filamentation and chirped mirror compression in noble gasses [68].

\section{Concluding remarks}

In conclusion, nonlinear $\mathrm{X}$ waves exhibit a very localized peak, in both transverse and longitudinal (temporal) coordinates, which propagates free of diffraction and dispersion, even in dispersive materials, for distances far exceeding those achievable with conventional Gaussian-like beams. The discovery of spontaneous formation of nonlinear $\mathrm{X}$ waves in transparent dispersive media has put forward a novel understanding of light-matter interactions, widely opened new fundamental issues, and already suggested numerous applications requiring energy transfer to matter over very limited transverse areas in thick media and which thus suffer the short focal depth of conventional beams. It has to be noted that linear and nonlinear conical waves 
are subject to many areas of physics. The generality of wave localization phenomena allows one to make use of these results in other physical systems, such as matter waves in Bose-Einstein condensates, where ultracold atoms behave like quantum mechanical wave packets [69] and Langmuir waves in plasmas [70]. In acoustics, localized sound waves are desirable for enhanced resolution in ultrasonic imaging, and interestingly, linear X waves in acoustics were demonstrated 5 years earlier than in optics [71]. Propagation of localized microwaves over distances of tens of wavelengths [72], as well as preliminary experiments in localization of terahertz radiation [73] and radio waves [74] had been reported to date. Conical waves are well known in astrophysics - a light from distant objects, distorted by gravitational lenses is transformed into a conical wave, which carries the information not accessible by other means (because of limited angular resolution, for instance) about the object as well as about the structure of the Universe [75].

\section{Acknowledgements}

We gratefully acknowledge Prof. A. Piskarskas for deep scientific discussions, Dr R. Danielius and Dr G. Tamošauskas (all are with Vilnius University) for their skills and support in experiments. We also thank Prof. P. Di Trapani from Insubria University (Como, Italy) for a longstanding and fruitful collaboration, Prof. M.A. Porras (Universidad Politécnica de Madrid, Spain) and Dr A. Couairon (Centre de Physique Théorique, Palaiseau, France) for their help in developing numerical models and providing excellent numerical simulations.

\section{References}

[1] F. Wise and P. Di Trapani, The hunt for light bullets spatiotemporal solitons, Opt. Photon. News 13(2), 2732 (2002).

[2] J. Scott Russell, Report on waves, in: Report of the XIV Meeting of the British Association for the Advancement of Science, York, September 1844, pp. 311-390.

[3] L.F. Mollenauer, R.H. Stolen, and J.P. Gordon, Experimental observation of picosecond pulse narrowing and solitons in optical fibers, Phys. Rev. Lett. 45, 10961099 (1980).

[4] Y. Silberberg, Collapse of optical pulses, Opt. Lett. 15, 1282-1284 (1990).

[5] M. Ablowitz, G. Biondini, and L.A. Ostrovsky, Optical solitons: Perspectives and applications, Chaos 10, 471-474 (2000). For a review on $\chi^{2}$ soltons see A.V. Buryak, P. Di Trapani, D.V. Skryabin, and S. Trillo, Optical solitons due to quadratic nonlinearities: From basic physics to futuristic applications, Phys. Rep. 370, 63-235 (2002).

[6] Y.F. Chen, K. Beckwitt, F. Wise, and B.A. Malomed, Criteria for the experimental observation of multidimensional optical solitons in saturable media, Phys. Rev. E 70, 046610 (2004).

[7] H. Bateman, The Mathematical Analysis of Electrical and Optical Wave Motion on the Basis of Maxwell's Equations (Dover, New York, 1955).

[8] J.A. Stratton, Electromagnetic Theory (McGraw Hill, New York, 1941).

[9] J. Durnin, Exact solutions for nondiffracting beams. I. The scalar theory, J. Opt. Soc. Am. A 4, 651-654 (1987).

[10] J. Durnin, J.J. Miceli, and J.H. Eberly, Diffraction-free beams, Phys. Rev. Lett. 58, 1499-1502 (1987).

[11] D. McGloin and K. Dholakia, Bessel beams: Diffraction in a new light, Contemporary Physics 41, 15-28 (2005).

[12] P. Saari and K. Reivelt, Evidence of X-shaped propagation-invariant localized light waves, Phys. Rev. Lett. 79, 4135-4138 (1997).

[13] M.A. Porras, Diffraction-free and dispersion-free pulsed beam propagation in dispersive medium, Opt. Lett. 26, 1364-1366 (2001).

[14] S. Orlov, A. Piskarskas, and A. Stabinis, Localized optical subcycle pulses in dispersive media, Opt. Lett. 27, 2167-2169 (2002).

[15] R. Grunwald, V. Kebbel, U. Neuman, M. Rini, E. Nibbering, M. Piché, G. Rousseau, and M. Fortin, Generation and characterization of spatially and temporally localized few-cycle optical wave packets, Phys. Rev. A 67063820 (2003).

[16] R.Y. Chiao, E. Garmire, and C.H. Townes, Selftrapping of optical beams, Phys. Rev. Lett. 13, 479482 (1964).

[17] L. Bergé, Wave collapse in physics: Principles and applications to light and plasma waves, Phys. Rep. 303, 259-370 (1998).

[18] A.L. Gaeta, Collapsing light really shines, Science 301, 54-55 (2003).

[19] A. Braun, G. Korn, X. Liu, D. Du, J. Squier, and G. Mourou, Self-channeling of high-peak-power femtosecond laser pulses in air, Opt. Lett. 20, 73-75 (1995).

[20] J.V. Moloney, M. Kolesik, M. Mlejnek, and E.M. Wright, Femtosecond self-guided light strings, Chaos 10, 559-569 (2000).

[21] A. Couairon, S. Tzortzakis, L. Bergé, M. Franco, B. Prade, and A. Mysyrowicz, Infrared femtosecond light filaments in air: Simulations and experiments, J. Opt. Soc. Am. B 19, 1117-1131 (2002).

[22] W. Liu, S.A. Hosseini, Q. Luo, B. Ferland, S.L. Chin, O.G. Kosareva, N.A. Panov, and V.P. Kandidov, 
Experimental observation and simulations of the selfaction of white light laser pulse propagating in air, New J. Phys. 6, 6.1-6.22 (2004).

[23] S. Tzortzakis, L. Sudrie, M. Franco, B. Prade, A. Mysyrowicz, A. Couairon, and L. Bergé, Selfguided propagation of ultrashort IR laser pulses in fused silica, Phys. Rev. Lett. 87, 213902 (2001).

[24] A. Couairon, L. Sudrie, M. Franco, B. Prade, and A. Mysyrowicz, Filamentation and damage in fused silica induced by tightly focused femtosecond laser pulses, Phys. Rev. B 71, 125435 (2005).

[25] A. Brodeur, F.A. Ilkov, and S.L. Chin, Beam filamentation and the white light continuum divergence, Opt. Commun. 129, 193-198 (1996).

[26] A. Dubietis, G. Tamošauskas, I. Diomin, and A. Varanavičius, Self-guided propagation of femtosecond light pulses in water, Opt. Lett. 28, 1269-1271 (2003).

[27] W. Liu, S.L. Chin, O.G. Kosareva, I.S. Golubtsov, and V.P. Kandidov, Multiple refocusing of a femtosecond laser pulse in a dispersive liquid (methanol), Opt. Commun. 225, 193-209 (2003).

[28] A. Couairon, E. Gaižauskas, D. Faccio, A. Dubietis, and P. Di Trapani, Nonlinear X-wave formation by femtosecond filamentation in water, Phys. Rev. E (submitted).

[29] A. Dubietis, E. Gaižauskas, G. Tamošauskas, and P. Di Trapani, Light filaments without self-channeling, Phys. Rev. Lett. 92, 253903 (2004).

[30] A. Dubietis, E. Kučinskas, G. Tamošauskas, E. Gaižauskas, M.A. Porras, and P. Di Trapani, Self-reconstruction of light filaments, Opt. Lett. 29, 2893-2895 (2004).

[31] M. Kolesik and J.V. Moloney, Self-healing femtosecond light filaments, Opt. Lett. 29, 590-592 (2004).

[32] W. Liu, J.-F. Gravel, F. Théberge, A. Becker, and S.L. Chin, Background reservoir: Its crucial role for long-distance propagation of femtosecond laser pulses in air, Appl. Phys. B 80, 857-860 (2005).

[33] M.A. Porras, A. Parola, D. Faccio, A. Dubietis, and P. Di Trapani, Nonlinear unbalanced Bessel beams: Stationary conical waves supported by nonlinear losses, Phys. Rev. Lett. 93, 153902 (2004).

[34] G. Valiulis, J. Kilius, O. Jedrkiewicz, A. Bramati, S. Minardi, C. Conti, S. Trillo, A. Piskarskas, and P. Di Trapani, Space-time nonlinear compression and three-dimensional complex trapping in normal dispersion, in: Trends in optics and photonics, Vol. 57, postdeadline paper QPD10-1 (Optical Society of America, Washington DC, 2001).

[35] C. Conti, S. Trillo, P. Di Trapani, G. Valiulis, A. Piskarskas, O. Jedrkiewicz, and J. Trull, Nonlinear electromagnetic X-waves, Phys. Rev. Lett. 90, 170406 (2003).

[36] P. Di Trapani, G. Valiulis, A. Piskarskas, O. Jedrkiewicz, J. Trull, C. Conti, and S. Trillo, Sponta- neously generated X-shaped light bullets, Phys. Rev. Lett. 91, 093904 (2003).

[37] O. Jedrkiewicz, J. Trull, G. Valiulis, A. Piskarskas, C. Conti, S. Trillo, and P. Di Trapani, Nonlinear X waves in second-harmonic generation: Experimental results, Phys. Rev. E 68, 026610 (2003).

[38] J. Trull, O. Jedrkiewicz, P. Di Trapani, A. Matijošius, A. Varanavičius, G. Valiulis, R. Danielius, E. Kučinskas, and A. Piskarskas, Spatiotemporal threedimensional mapping of nonlinear $\mathrm{X}$ waves, Phys. Rev. E 69, 026607 (2004).

[39] M.A.C. Potenza, S. Minardi, J. Trull, G. Blasi, D. Salerno, A. Varanavičius, A. Piskarskas, and P. Di Trapani, Three dimensional imaging of short pulses, Opt. Commun. 229, 381-390 (2004).

[40] M. Kolesik, E.M. Wright, and J.V. Moloney, Dynamic nonlinear $\mathrm{X}$ waves for femtosecond pulse propagation in water, Phys. Rev. Lett. 92, 253901 (2004).

[41] C. Day, Intense X-shaped pulses of light propagate without spreading in water and other dispersive media, Phys. Today 57(10), 25-27 (2004).

[42] A. Matijošius, J. Trull, P. Di Trapani, A. Dubietis, R. Piskarskas, A. Varanavičius, and A. Piskarskas, Nonlinear space-time dynamics of ultrashort wave packets in water, Opt. Lett. 29, 1123-1125 (2004).

[43] D. Faccio, P. Di Trapani, S. Minardi, A. Bramati, F. Bragheri, C. Liberale, V. Degiorgio, A. Dubietis, and A. Matijošius, Far-field spectral characterization of conical emission and filamentation in Kerr media, J. Opt. Soc. Am. B 22, 862-869 (2005).

[44] D. Faccio, A. Matijošius, A. Dubietis, R. Piskarskas, A. Varanavičius, E. Gaižauskas, A. Piskarskas, A. Couairon, and P. Di Trapani, Near- and far-field evolution of laser pulse filaments in Kerr media, Phys. Rev. E 72, 037601-1-4 (2005).

[45] K.D. Moll and A.L. Gaeta, Role of dispersion in multiple-collapse dynamics, Opt. Lett. 29, 995-997 (2004).

[46] L. Bergé and S. Skupin, Self-channeling of ultrashort laser pulses in materials with anomalous dispersion, Phys. Rev. E 71, 065601(R) (2005).

[47] M.A. Porras, A. Parola, and P. Di Trapani, Nonlinear unbalanced $\mathrm{O}$ waves: Nonsolitary, conical light bullets in nonlinear dissipative media, J. Opt. Soc. Am. B 22, 1406-1413 (2005).

[48] R. Butkus, S. Orlov, A. Piskarskas, V. Smilgevičius, and A. Stabinis, Phase matching of optical X-waves in nonlinear crystals, Opt. Commun. 244, 411-421 (2005).

[49] S. Longhi and D. Janner, X-shaped waves in photonic crystals, Phys. Rev. B 70, 235123 (2004).

[50] S. Droulias, K. Hizanidis, J. Meier, and D.N. Christoduolides, $\mathrm{X}$-waves in nonlinear normally dispersive waveguide arrays, Opt. Express 13, 1827-1832 (2005).

[51] J. Kasparian, M. Rodriguez, G. Mejéan, J. Yu, R. Bourayou, S. Frey, Y.B. André, A. Mysyrowicz, 
R. Sauerbrey, J.P. Wolf, and L. Wöste, White-light filaments for atmospheric analysis, Science 301, 61-64 (2003).

[52] M. Rodriguez, R. Bourayou, G. Mejéan, J. Kasparian, J. Yu, E. Salmon, A. Scholz, B. Stecklum, J. Eisloffel, U. Laux, A.P. Hatzes, R. Sauerbrey, L. Wöste, and J.-P. Wolf, Kilometer-range nonlinear propagation of femtosecond laser pulses, Phys. Rev. E 69, 036607 (2004).

[53] H.R. Lange, A. Chiron, J.-F. Ripoche, A. Mysyrowicz, P. Breger, and P. Agostini, High-order harmonic generation and quasiphase matching in xenon using selfguided femtosecond pulses, Phys. Rev. Lett. 81 16111614 (1998).

[54] Q. Luo, S.A. Hosseini, and W. Liu, Lasing action in air induced by ultrafast laser filamentation, Opt. Photon. News 15(9), 44-47 (2004).

[55] X.M. Zhao, J.C. Diels, C.Y. Wang, and J.M. Elizondo, Femtosecond ultraviolet laser pulse induced lightning discharges in gasses, IEEE J. Quantum Electron. 31, 599-612 (1995).

[56] M. Rodriguez, R. Sauerbrey, H. Wille, L. Wöste, T. Fujii, Y.-B. André, A. Mysyrowicz, L. Klingbeil, K. Rethmeier, W. Kalkner, J. Kasparian, E. Salmon, J. Yu, and J.-P. Wolf, Triggering and guiding megavolt discharges by use of laser-induced ionized filaments, Opt. Lett. 27, 772-774 (2002).

[57] R. Ackermann, K. Stelmarczyk, P. Rohwetter, G. Mejéan, E. Salmon, J. Yu, J. Kasparian, G. Mechain, V. Bergmann, S. Schaper, B. Weise, T. Kumm, K. Rethmeier, W. Kalkner, L. Wöste, and J.-P. Wolf, Triggering and guiding of megavolt discharges by laser-induced filaments under rain conditions, Appl. Phys. Lett. 85, 5781-5783 (2005).

[58] V. Garcez-Chavez, D. McGloin, H. Melville, W. Sibbett, and K. Dholakia, Simultaneous micromanipulation in multiple planes using a self-reconstructing light beam, Nature 419, 145-147 (2002).

[59] V. Garces-Chavez, D. Roskey, M.D. Summers, H. Melville, D. McGloin, E.M. Wright, and K. Dholakia, Optical levitation in a Bessel light beam, Appl. Phys. Lett. 85, 4001-4003 (2004).

[60] J.Y. Ye, G. Chang, T.B. Norris, C. Tse, M.J. Zohdy, K.W. Hollman, M. O'Donnell, and J.R. Baker Jr, Trapping cavitation bubbles with a self-focused laser beam, Opt. Lett. 29, 2136-2138 (2004).

[61] M. Erdelyi, Z.L. Horvath, G. Szabo, Zs. Bor, F.K. Tittel, J.R. Cavallaro, and M.C. Smayling, Generation of diffraction-free beams for applications in optical microlithography, J. Vac. Sci. Technol. B 15, 287-292 (1997).
[62] J. Amako, D. Sawaki, and E. Fujii, Microstructuring transparent materials by use of nondiffracting ultrashort pulse beams generated by diffractive optics, J. Opt. Soc. Am. B 20, 2562-2568 (2003).

[63] K. Yamada, W. Watanabe, T. Toma, K. Itoh, and J. Nishii, In situ observation of photoinduced refractive-index changes in filaments formed in glasses by femtosecond laser pulses, Opt. Lett. 26, 19-21 (2001).

[64] P. Polesana, D. Faccio, P. Di Trapani, A. Dubietis, A. Piskarskas, A. Couairon, and M.A. Porras, High localization, focal depth and contrast by means of nonlinear Bessel beams, Opt. Express 13, 6160-6167 (2005).

[65] T. Wulle and S. Herminghaus, Nonlinear optics of Bessel beams, Phys. Rev. Lett. 70, 1401-1403 (1993).

[66] A. Piskarskas, V. Smilgevičius, A. Stabinis, and V. Jarutis, Output patterns of optical parametric amplifiers and generators pumped by conical beams, J. Opt. A 1, 52-57 (1999).

[67] S.L. Chin, A. Brodeur, S. Petit, O.G. Kosareva, and V.P. Kandidov, Filamentation and supercontinuum generation during the propagation of powerful ultrashort laser pulses in optical media (White Light Laser), J. Nonlinear Opt. Phys. Mat. 8, 121-146 (1999).

[68] C.P. Hauri, W. Kornelis, F.W. Helbing, A. Heinrich, A. Couairon, A. Mysyrowicz, J. Biegert, and U. Keller, Generation of intense, carrier-envelope phase-locked few-cycle laser pulses through filamentation, Appl. Phys. B 79, 673-677 (2004).

[69] C. Conti and S. Trillo, Nonspreading wave packets in three dimensions formed by an ultracold Bose gas in an optical lattice, Phys. Rev. Lett. 92, 120404 (2004).

[70] M. Landman, G. Papanicolaou, C. Sulem, P. Sulem, and X. Wang, Stability of isotropic self-similar dynamics for scalar-wave collapse, Phys. Rev. A 46, 78697876 (1992).

[71] J. Lu and J.F. Greenleaf, Experimental verification of nondiffracting $\mathrm{X}$ waves, IEEE Trans. Ultrason. Ferroel. Freq. Control 39, 441-446 (1992).

[72] D. Mugnai, A. Ranfagni, and R. Ruggeri, Observation of superluminal behaviors in wave propagation, Phys. Rev. Lett. 84, 4830-4833 (2000).

[73] Z. Jiang and X.-C. Zhang, 2D measurement and spatiotemporal coupling of few-cycle THz pulses, Opt. Express 5, 243-248 (1999).

[74] J. Salo, J. Meltaus, E. Noponen, J. Westerholm, M. Salomaa, A. Lonnquist, J. Saily, A. Hakli, J. AlaLaurinaho, and A. Raisanen, Millimetre-wave Bessel beams using computer holograms, Electron. Lett. 37, 834-835 (2001).

[75] L.M. Soroko, Mesooptics (World Scientific, Singapore, 1996). 


\title{
NETIESINĖ ŠVIESOS LOKALIZACIJA
}

\author{
A. Dubietis, G. Valiulis, A. Varanavičius
}

Vilniaus universitetas, Vilnius, Lietuva

\section{Santrauka}

Vienas aktualiausių šiuolaikinès optikos uždavinių - rasti būdus ir sąlygas, kaip išvengti itin trumpu bangu paketu (lazerio pluoštu ir impulsų) plètros, kurią lemia dispersija ir difrakcija. Toks uždavinys yra svarbus tiek fundamentiniu, tiek ir praktiniu požiūriu. Neseniai atrastos netiesinès kūginès $\mathrm{X}$ bangos atveria galimybes formuoti naujo tipo sutelktos energijos darinius (šviesos kulkas) ir valdyti jų savybes, vykstant stipriai šviesos sąveikai su medžiaga. Apžvelgti naujausi netiesinès optikos pasiekimai šviesos lokalizacijos srityje, siūlantys naują požiūrị i šviesos saviveikos reiškinius bei išryškinantys laiko ir erdvès reiškiniu neatsiejamumą. Aptartos kokybiškai naujų šviesos dariniu - netiesinių X bangų (šviesos kulkų) savaiminio radimosi skaidriose medžiagose prielaidos, dèsningumai ir eksperimentinio realizavimo būdai. Unikalios šviesos kulkų savybės - platus dažniu spektras, didelè energijos sankaupa mažame erdvès tūryje ir laiko intervale, sklidimo nuostovumas, taip pat galimybè valdyti jų parametrus - atveria plačias taikymo galimybes ten, kur iprastinių lazerio pluoštų taikymas yra neefektyvus, o kartais net ir sunkiai įmanomas. 